\title{
Co-Creation of Value in IT Service Processes using Semantic MediaWiki
}

\author{
Rainer Schmidt ${ }^{1}{ }^{\text {Frank Dengler }}{ }^{2}$ Axel Kieninger ${ }^{3}$ \\ ${ }^{1}$ HTW-Aalen, now on sabbatical at Karlsruhe Service Research Institute \\ ${ }^{2}$ Institute AIFB, Universität Karlsruhe (TH) \\ ${ }^{3}$ Karlsruhe Service Research Institute, Universität Karlsruhe (TH) \\ Rainer.Schmidt@,htw-aalen.de \\ Frank.Dengler@kit.edu \\ Axel.Kieninger@ksri.uni-karlsruhe.de
}

\begin{abstract}
Enterprises are substituting their own IT-Systems by services provided by external providers. This provisioning of services may be done in an industrialized way, separating the service provider from the consumer. However, using industrialized services diminishes the capability to differentiate from competitors. To counter this, collaborative service processes based on the co-creation of value between service providers and prosumers are of huge importance. The approach presented shows how the co-creation of value in ITservice processes can profit from social software, using the example of the Semantic MediaWiki.
\end{abstract}

Keywords: Service, Process, SD-Logic, Co-Creation, Semantic MediaWiki

\section{Introduction}

Offering and using IT-services is becoming more and more important for many enterprises. Customers substitute owning IT-systems by service [1] [2]. They request IT-services instead of IT-systems and IT-enterprises have to change their offer to fulfil this changing demand. Using service helps customer enterprises to facilitate outsourcing and thus allows them to concentrate on their core competencies. The innovative potential of IT-services has been an important topic of discussion and lead to the term service science [3][4]. Some see IT as a commodity [5]. Using commoditized, industrialized IT-services may create cost benefits. However, an enterprise using commoditized IT-services diminishes its capability to differentiate from competitors. By contrast, individualized services are necessary to differentiate from competitors. Therefore, enterprises should use a mixture of industrialized commodity services for cost-cutting and individualized services for differentiation [6]. The ratio between these two has to be selected according to enterprises' strategies.

In Service Dominant Logic (SD-Logic) [7], developed by Vargo and Lusch, a "service is defined as the application of specialized competences (knowledge and 
skills) for the benefit of another entity, rather than the production of units of output" [7] ${ }^{1}$. The co-creation of value and not the output of production should be in the centre of interest (The term value will be regarded in more detail within the next paragraph). Thus service is regarded as a process of interaction with the customer and not as an interface to the customer. Value is co-created in a service process by a service provider and his customer as shown in Fig. 1, instead of producing a good and delivering it to the customer. Therefore it is better to name the role of the customer as prosumer [8][9].

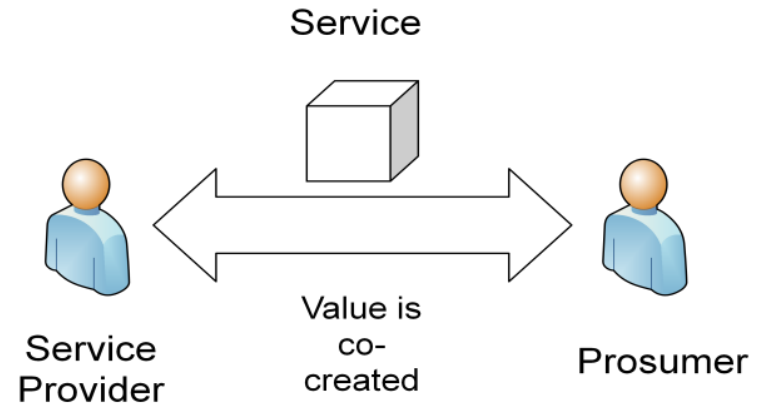

Fig. 1 : SD-Logic

Service-Dominant Logic is not an isolated theory, but is related to a number of emerging ideas, from which several showed their applicability. Thus, SD-Logic is embedded in a stream of ideas and thoughts that emphasize the collaboration of independent individuals to co-create value. The co-creation of value is described in its general form, that means also for material goods, in [10] and [11]. The integration of the customer into value creation is based on the conviction that putting together the contributions of many different stakeholders, a better result can be achieved than by expert decisions. Therefore, the wisdom of the crowds [12] is an important foundation for co-creation of value. The most prominent approach is the collaborative creation of software following an open source approach, following Linus' law instead of Brook's law [13]. Behind these ideas, there is the possibility to create a new kind of economy, as discussed by Benkler in [14]. Co-creation of value also influences the discussion about intellectual property [15].

The contribution of this paper is to show how the co-creation of value in IT-service processes can profit from social software, using the example of a Semantic MediaWiki [16]. The paper proceeds as follows: first, the notion of value created in service processes and its implications are discussed in more detail. Then, service processes and their elements are introduced. In the next sections, the co-creation of value is introduced and the obstacles to achieve it are analysed. Afterwards a concept for the co-creation of service specifications using a Semantic MediaWiki is

1 The services discussed here are not services, which are part of so-called service-oriented architectures [33]. A service in the context of SOA is a special kind of interface for an encapsulated unit of software and thus something completely different than the services discussed here. However, the services considered in this article may be part of a Service Oriented Enterprise Architecture (SOEA) [34] 
developed. An application scenario shows the use of the concept developed in practice. Finally, the results are discussed and a summery is given.

\section{Value of services}

Before we discuss the co-creation of value, we give a definition of the term value. For a long time, only the final effects of service have been of interest and influenced the notion of value of service (e.g. that a good has been transported from A to B). More and more also the way how service has been provided became important (for example, if the good arrived in time). Therefore also non-functional properties have been incorporated into the notion of value. However, functional and non-functional properties do not capture a number of features of service, which are important for the customer, but are on a higher abstraction level. This third dimension is created by management interactions between the service provider and the prosumer. A basic example of a management interaction is the complaint about an inadequate service. Further examples are changes to functional and non-functional properties of the service. Based on these considerations, the value created by services can be interpreted as the product of three dimensions: Functional-properties, non-functionalproperties and management interactions, as shown in Fig. 2.

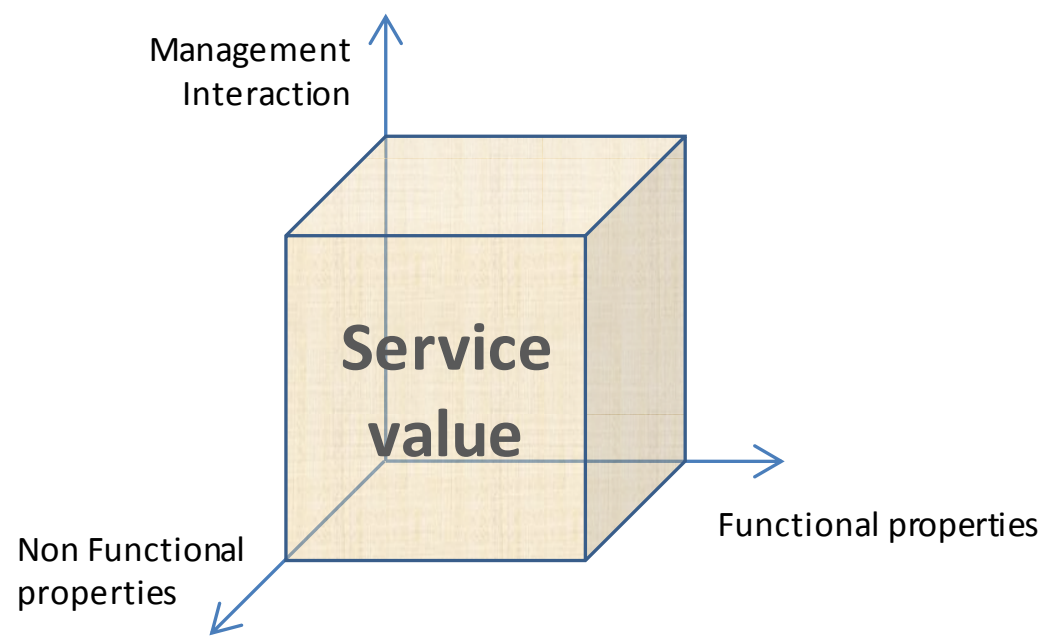

Fig. 2 : Value created by service

\section{Service Processes}

Service is a process "consisting of a series of activities where a number of different types of resources are used in direct interaction with a customer, so that a solution is 
found to a customer's problem" [17]. Active and passive resources are involved in service. Active resources act on passive resources to create service. In SD-Logic, active resources are called operant resources; passive resources are called operand resources [18]. Service processes have many properties in common with ordinary business processes. However, there are also a number of crucial differences [19]. There are interactions with the customer to co-create value: So-called critical incidents are specific encounters resulting in satisfaction or dissatisfaction of the customer [1]. It is necessary to know, that there may be obligations of the customer that are critical for success or failure of the service process. For example, it may be necessary that the customer provides some information required for the further proceeding of the process.

During the recent years non-functional properties of services have been widely discussed in literature as for example in the field of Software Engineering (see e.g. [20], [21], [22] ). In [23] O'Sullivan examines these properties of services in general, abstracting from a particular (computer) science field's perspective. According to his work non-functional properties of services are constraints associated to services' functionality and may be divided into nine different classes. In the following these groups - namely availability, price, payment, discounts and penalties, obligations, rights, quality, security and trust - are briefly introduced.The availability of a service defines the time (when) or the location (where) a prosumer is able to accept a provider's proposition to co-create value. Regarding the price of a service there are different charging techniques a provider may select to specify the value of his work. The amount of money a prosumer is charged can depend on proposition activities (e.g. enabling service availability) as well as on co-creation activities (e.g. units of measure co-created) of the provider. The corresponding payment process is agreed on in the beginning of a service relationship. There may be discounts a prosumer receives depending on terms of payment (payment related discounts i.e. how to pay) or on attributes of the prosumer himself (payee related discounts as e.g. membership to associations). Within the scope of their cooperation a prosumer and a provider agree to meet certain obligations (as for example to provide operand or operant resources). In case of non-compliance with these obligations the respective party will be penalized i.e. has to bear the consequences defined. By now the provider usually owns the intellectual property associated with a service process. A prosumer just has a limited set of rights (as for example the right to comprehend, the right to retract, the right of premature termination, the right of suspension and the right of resumption). However the co-creation of service process specifications will influence on the contemporary legal situation. The quality of a service should be assessed from a prosumer's point of view. Security aspects are of increasing interest - particularly with respect to IT-enabled services. Managing security means to reduce concerns regarding identity, privacy, alteration etc. The same applies for mutual trust between the parties involved in a service relationship, which is of high importance. 


\section{Co-Creation of Value}

Co-creation of value requires changing the locus of interaction [10]. To co-create value, the interaction between service provider and customer has to come about along the whole value chain. In industrialized production the interaction takes place at the end of the value chain.

Unfortunately, there are a number of obstacles for the co-creation of value in service processes. The most important one are thresholds for the passing-on of information between stakeholders and the lack of information fusioning (Fig. 3).

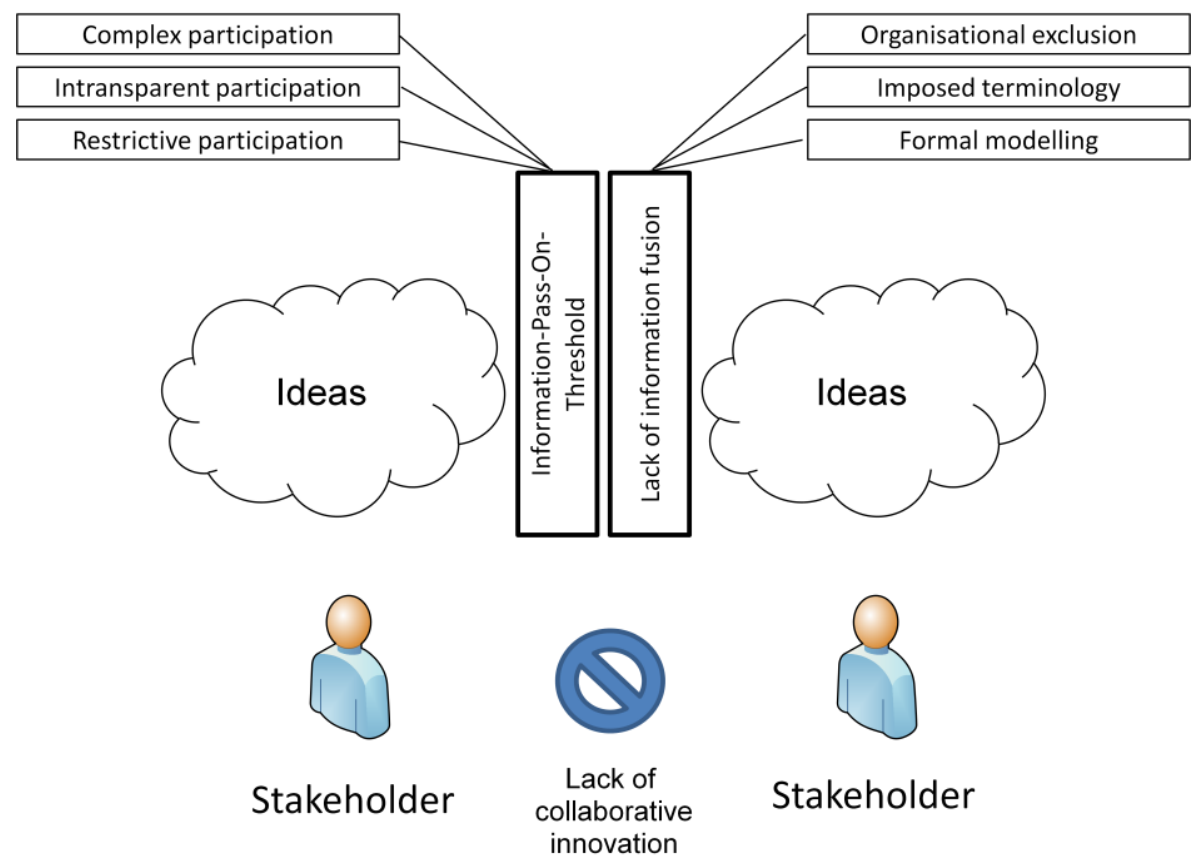

Fig. 3 : Obstacles for the co-creation of value

Information pass-on threshold: Ideas for improvement are not exchanged between stakeholders because this creates too much effort ("Why shall I write a memo or a letter"). The further processing is not transparent to the stakeholders ("What will happen to my suggestion...") or the success is considered as improbable ("Will not succeed anyway ..."). The information pass-on-threshold may also be increased if the entering of information is strongly regulated; the process to submit changes is too restrictive or simply takes too long due to approval steps. This causes that stakeholders cannot bring in easily their ideas. Important and valuable information is lost and improvements remain undone.

Lack of information fusion: The other important obstacle for value co-creation is the lack of information fusion. Even if the organizational environment allows the 
stakeholders to contribute they are partially excluded because the terms used to describe services are defined without their participation or simply imposed on them. Often, stakeholders are excluded due to the project organisation or because they have not been taught to use formal modelling methods. Thus stakeholders are only "consumers" of the terms created and are forced to accept those. Therefore, they tend to retain contributions.

\section{Using Semantic MediaWiki to support Value Co-Creation}

In order to address the issues mentioned in the previous sections we propose the use of a Semantic MediaWiki (SMW). SMW extends the MediaWiki software that runs the popular Wikipedia site. The extension combines the collaborative aspects of wikis [24] with Semantic Web technology to enable large-scale and interdepartmental collaboration on knowledge structures. Users can express their knowledge with their natural language combined with formal annotations allowing machines to process this knowledge. For this purpose SMW enables the user to define class hierarchies and semantic properties related to wiki pages. In our application functional and non-functional properties as well as annotated links to management interactions can thus be discussed. SMW stores this expressed knowledge and makes it easy accessible for all users by providing an inline query language. This language enables users to query for semantic properties and classes. An inline query for example could ask for all services, their corresponding process owners and the people involved into the process. SMW also act as a repository for service management processes, which can be reused for new services and collaboratively refined by the parties involved. In addition to that SMW offers RDF export functionalities. Thus knowledge in SMW can be used by other applications.

Fig. 4 gives an overview how the issues identified above can be solved by using SMW. In the following we want to show in detail how using SMW can reduce the deficiencies of existing requirements elicitation approaches. 


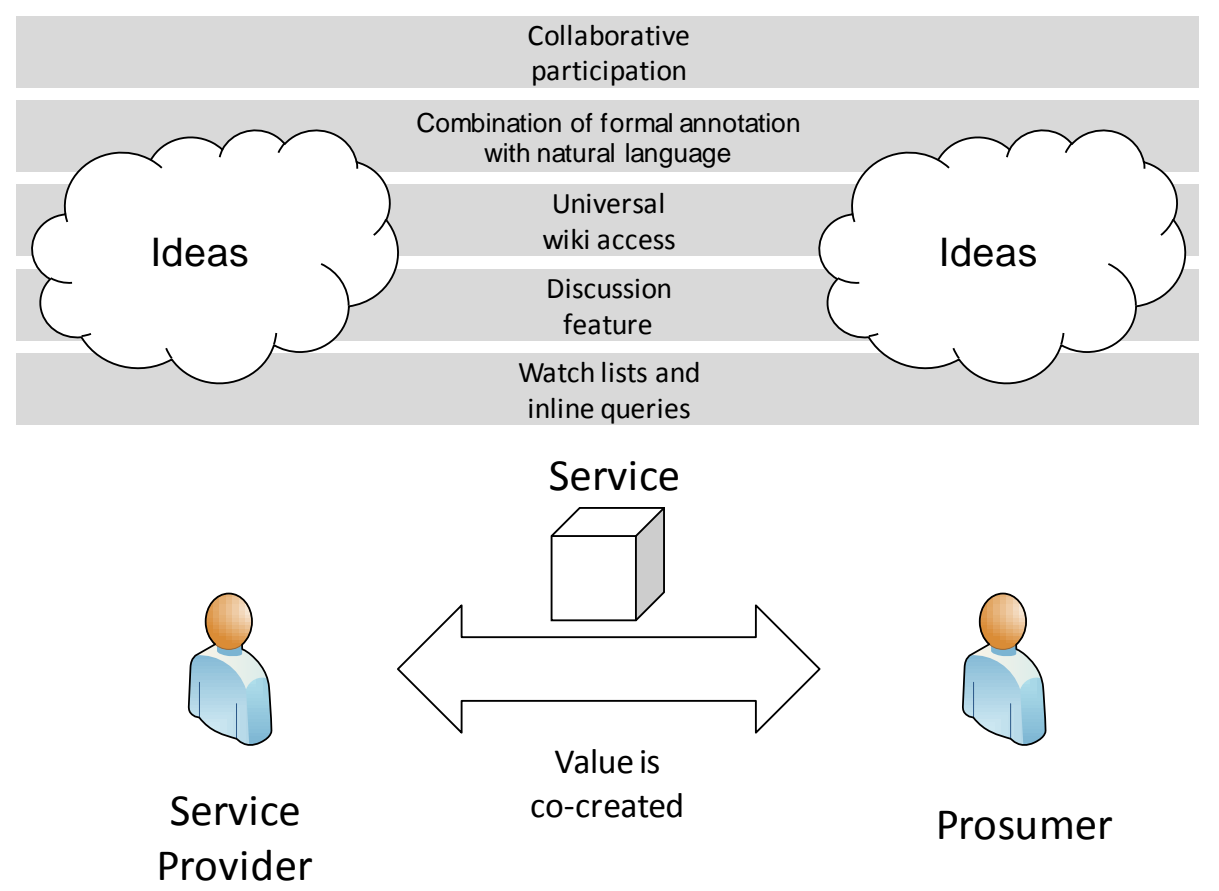

Fig. 4 : Issues addressed

Reduction of the information pass-on threshold: Service providers and prosumers can participate in the process by expressing collaboratively their ideas in SMW. The responsible persons can also access the SMW. Thus the ideas are forwarded directly to the responsible stakeholder. SMW features like watch list and inline queries can be used to support this information flow. Each SMW user can register wiki pages in his watch list. When someone updates the watched wiki page, the user gets a notification by email. Inline queries can be used to show relevant information on wiki pages dynamically. For instance, all relevant information in SMW about one process can be displayed on a dynamic created summary page [25]. The effort for each user is also lower, because the ideas can be developed collaboratively. A user can pick up an idea of another user and broaden it. The versioning capability of SMW allows tracing the changes of each user. Different versions can also be compared with each other. Important information is stored within the SMW and ideas as well as improvements can directly be represented in the process definition. The process to submit changes is not restrictive anymore. In addition to that the users can see in SMW what has happened with their suggestion by using for example the watch list or inline queries as stated above for the responsible persons. Now, the further processing is more transparent to them.

Lack of information fusion: Information fusion can be promoted by using SMW. All stakeholders and thus the users can access the SMW and thus participate in 
service process modelling. No one is excluded by organisational means. Existing service management processes can easily be linked to emerging services and refined if necessary. Thus existing information is reused and it is less time-consuming for the parties involved as starting from scratch. The users are able to use their natural language in combination with formal annotations. Thus the user describes the process with his own language and adds classes and semantic properties in his text. This fact lowers the participation barrier that exists through the use of a formalised modelling tool. Users in companies are familiar with the wiki syntax, because it is easy to apply and many of them have used it before. The effort the user has to invest to learn modelling processes is low. Users are not only "consumers" anymore who are forced to accept the processes created for them (e.g. by externals), but active participants. In addition to that all users can contribute to the definition of terms in a collaborative way. That can be realized by additional wiki pages, like a glossary, or by using the discussion functionality provided by SMW. Thus users can discuss and evolve the meaning of terms.

As a conclusion SMW can support requirement elicitation by addressing most of the deficiencies of existing approaches. Other advantages of using SMW are the template functionality of MediaWiki ${ }^{2}$ and existing extensions for SMW like Semantic Forms $^{3}$, which provide more user-friendly forms to enter semantic annotations into SMW.

\section{Application scenario}

The concepts introduced above have been used to support the IT-service processes of a gardening tool manufacturer [26]. The IT department of this manufacturer looked for a tool to improve the cooperation with business units.

Before, the business units did not contribute much and there has been little transparency regarding the services to be offered and their properties. Furthermore, the design of new services has been a very painful process. Customers' requirements could not be identified in full extent, because there had been information pass-on thresholds and a lack of information fusion. The business units did not use the tools offered by the IT department and used other terms to describe services. Therefore, the IT department often designed IT-services and respective Service Level Agreements (SLAs) without proper contribution of the business units. However, after service implementation, the business units often complained about lacks of alignment with their requirements.

\footnotetext{
${ }^{2}$ http://www.mediawiki.org/wiki/Help:Templates

${ }^{3} \mathrm{http}: / /$ www.mediawiki.org/wiki/Extension:Semantic_Forms
} 

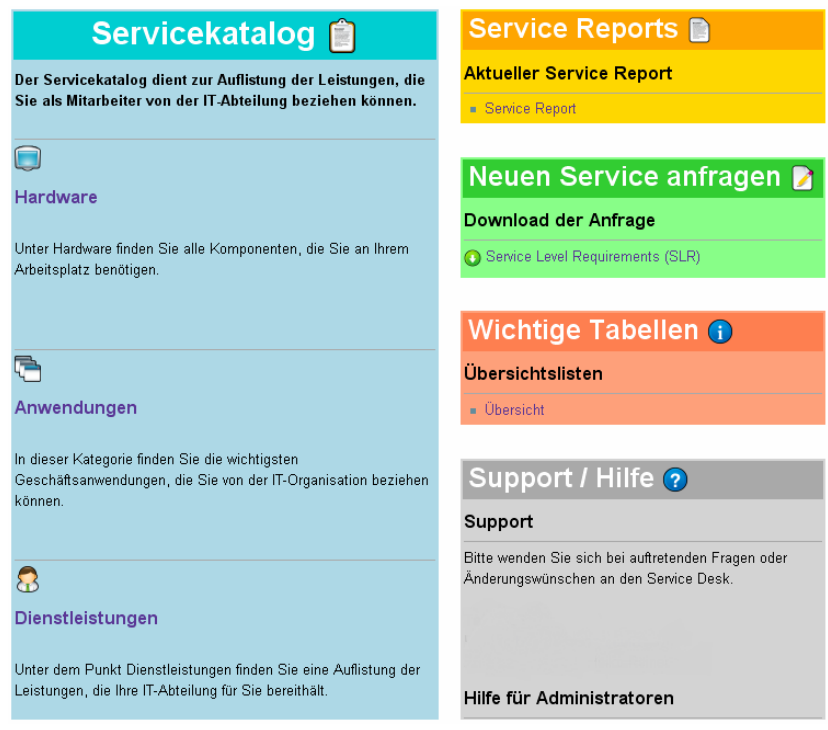

Fig. 5. Screenshot of user interface [26]

To adress these issues, a Semantic MediaWiki based solution has been created. It contains a catalogue with the services already implemented including the associated Service Level Agreements. Reports of the service performance are also available. The most important features are service proposals. By this means, business units are able to easily enter their suggestions for new services or improvements of services. The information flow has been improved, because suggestions are visible to all stakeholders. Business units can use natural language to describe their requirements, which then are annotated by the IT department. Inline queries are used to summarize all relevant information concerning a service proposal. By using a watch list, all users get informed about changes relevant to them. Using the collaborative features of Semantic MediaWiki, the effort of the business units to create suggestions is much lower, because they can profit from already made contributions.

By the application of Semantic MediaWiki a much more homogenous use of terms has been achieved. Participation barriers that existed before - especially for the business units - have been abolished. A screen shot of the user interface is shown in Fig. 5. The information is structured in a better way and every individual information demand can be addressed by providing a customized view generated with inline queries.

\section{Related work}

A fundamental analysis of value and value co-creation in services is done in [27]. A conceptual analysis of co-creation of value is made in [28]. Especially the debate of value-in-use vs. value-in-exchange is considered in a very detailed manner. Especially 
the importance to interact with the customer and to use small steps for innovation is emphasized. Differences between goods and service innovation are analysed in [29]. The importance to collaborate and to co-create value in services to achieve a strategic advantage is examined in [30]. The importance to interact with the customer in general is shown in [10]. The nature of value co-creation in services is analyzed in [31]. In [32] the role of the customer in new service development is discussed.

\section{Discussion}

The integration of the customer as prosumer does not only provide advantages but also a couple of issues [10], which also appeared when using the Semantic MediaWiki application described above. First, using a social software solution is a drastic change for many employees who are used to hierarchic structures. Often, employees do not dare to contribute because they are not familiar with egalitarian approaches. Instead they wait for a management approval or initiative. On the other side, managers fear to lose control of their processes. They are accustomed to exactly defined change procedures, enabling perfect control over the entire process. Often, they just learn slowly, that social control can be much more effective than a tight governance structure.

When content is created collaboratively, the effort is higher. Furthermore, the time used for content creation cannot be easily associated with a person. Thus it is difficult to calculate the costs and to respect the time consumed in the task planning of the associated persons. This lack of resource control is of particular importance in the case of disputes. Then it is nearly impossible to quantify the effort caused by discussions etc. Another point is the distribution of responsibility. Due to the multiple contributors, the responsibility for the process design can no longer be associated with a distinct person. However, the process put into production needs a unique responsible process owner. To fulfil his responsibilities, the process owner also has to create a formal model of the collaboratively created model.

\section{Summary and conclusion}

Enterprise substitute owning IT-systems more and more by using IT-services. The value created by an IT-service can be increased by supporting the co-creation of value by the service provider and the prosumer, by providing knowledge as an active resource, and by tight cooperation during the execution of the respective service process. However, there are some obstacles for value co-creation such as information pass-on thresholds and a lack of information fusion. By using a Semantic MediaWiki it is possible to overcome most of these deficiencies. As also shown by the presented application scenario, the information and knowledge exchange between all stakeholders has been improved. Customers are no longer excluded from contributing ideas for improving service due to organizational or technical barriers and become true prosumers. Furthermore, the homogenisation of terms is facilitated and thus the fusion of information is improved. 


\section{Acknowledgements}

Research reported in this paper was partially funded by the European Commission through the IST project ACTIVE (ICT-FP7-215040). We would like to thank our colleagues at KSRI and AIFB for the many fruitful discussions. Special thanks go to $\mathrm{H}$. Reiner for conceptualizing and implementing the Semantic MediaWiki application.

\section{References}

[1] C.H. Lovelock and J. Wirtz, Services marketing, Prentice Hall Upper Saddle River, NJ, 2001.

[2] M.C. Lacity, L.P. Willcocks, and D.F. Feeny, "The value of selective IT sourcing," Sloan Management Review, vol. 37, 1996, pp. 13-25.

[3] J. Spohrer, P.P. Maglio, J. Bailey, and D. Gruhl, "Steps Toward a Science of Service Systems," COMPUTER, 2007, pp. 71-77.

[4] Jim Spohrer, "Steps Toward a Science of Service Systems," Jan. 2007.

[5] N.G. Carr, "IT Doesn't Matter," IEEE ENGINEERING MANAGEMENT REVIEW, vol. 32, 2004, pp. 24-32.

[6] A. McAfee, "Enterprise 2.0: the dawn of emergent collaboration," Engineering Management Review, IEEE, vol. 34, 2006, pp. 38-38.

[7] S.L. Vargo and R.F. Lusch, "Evolving to a new dominant logic for marketing," Journal of Marketing, vol. 68, 2004, pp. 1-17.

[8] A. Toffler, W. Longul, and H. Forbes, The third wave, Bantam Books New York, 1981.

[9] D. Tapscott and A.D. Williams, Wikinomics: How Mass Collaboration Changes Everything, Portfolio, 2006.

[10] C.K. Prahalad and V. Ramaswamy, "Co-creating unique value with customers," Strategy \& Leadership, vol. 32, 2004, pp. 4-9.

[11] E. von Hippel, Democratizing Innovation, MIT Press, 2005.

[12] J. Surowiecki, The Wisdom of Crowds: Why the Many Are Smarter Than the Few and How Collective Wisdom Shapes Business, Economies, Societies and Nations, Doubleday, 2004.

[13] A. Neus and P. Scherf, "Opening minds: Cultural change with the introduction of open-source collaboration methods," IBM Systems Journal, vol. 44, 2005, pp. 215-225.

[14] Y. Benkler, The Wealth of Networks: How Social Production Transforms Markets and Freedom, Yale University Press, 2006.

[15] L. Lessig, Remix: Making art and commerce thrive in the hybrid economy, Penguin Press, 2008.

[16] M. Krötzsch, D. Vrandecic, M. Völkel, H. Haller, and R. Studer, "Semantic Wikipedia," Web Semantics: Science, Services and Agents on the World Wide Web, vol. 5, Dec. 2007, pp. 251-261.

[17] C. Grönroos, Service Management and Marketing: A Customer Relationship Management Approach, Wiley, 2000. 
[18] S.L. Vargo and R.F. Lusch, "Evolving to a new dominant logic for marketing," Journal of Marketing, vol. 68, 2004, pp. 1-17.

[19] R. Schmidt, "Sercomp: A Component Oriented Method for Flexible Design and Support of Interorganizational Service," Software Process: Improvement and Practice, vol. 12, 2007, pp. 7-20.

[20] M. Glinz, "On non-functional requirements," Proc. RE, vol. 7, 2007, pp. 2126.

[21] L. Chung, "Representation and utilization of non-functional requirements for information system design," Advanced Information Systems Engineering, Proc., 3rd Int. Conf. CAiSE, Springer, , pp. 13-15.

[22] I. Sommerville, Software Engineering. 2004, Addison Wesley, .

[23] J.J. O'Sullivan, "Towards a precise understanding of service properties," 2006.

[24] B. Leuf and W. Cunningham, The Wiki way: quick collaboration on the Web, Addison-Wesley Longman Publishing Co., Inc. Boston, MA, USA, 2001.

[25] F. Dengler, S. Lamparter, M. Hefke, and A. Abecker, "Collaborative Process Development using Semantic MediaWiki," Proceedings of the 5th Conference of Professional Knowledge Management. Solothurn, Switzerland, 2009.

[26] H. Reiner, "Aufbau des Service Level Managements mithilfe eines Semantic MediaWiki+," Diploma Thesis, HTW Aalen, 2009.

[27] S.L. Vargo, P.P. Maglio, and M.A. Akaka, "On value and value co-creation: a service systems and service logic perspective," European Management Journal, vol. 26, 2008, pp. 145-152.

[28] A. Kambil, G.B. Friesen, and A. Sundaram, "Co-creation: A new source of value," Outlook Magazine, vol. 3, 1999, pp. 23-29.

[29] B. Tether, "Do Services Innovate (Differently)? Insights from the European Innobarometer Survey," Industry and Innovation, vol. 12, 2005, pp. 153-184.

[30] R.F. Lusch, S.L. Vargo, and M. Brien, "Competing through service: Insights from service-dominant logic," Journal of Retailing, vol. 83, pp. 5-18.

[31] A. Payne, K. Storbacka, and P. Frow, "Managing the co-creation of value," Journal of the Academy of Marketing Science, vol. 36, März. 2008, pp. 83-96.

[32] B.S.F. van der Wind, "The Use of Customers in the New Service Development Process.," Writer, vol. 4, pp. 9-2007.

[33] M.P. Papazoglou and W. Heuvel, "Service oriented architectures: approaches, technologies and research issues," The VLDB Journal, vol. 16, 2007, pp. 389415.

[34] M.W.A. Steen, P. Strating, M.M. Lankhorst, H. ter Doest, and M.E. Iacob, "Service-Oriented Enterprise Architecture," Service-oriented Software System Engineering: Challenges and Practices, 2005. 